\title{
Nota Farmacológica: ¿Son útiles los corticoides y los antivirales en el tratamiento de la parálisis facial idiopática?
}

\author{
Are steroids and antivirals useful in the treatment of idiopathic facial paralysis?
}

Catalina Brosens y Marcela Botargues*

\begin{abstract}
Resumen
Este artículo describe la evolución clínica y el pronóstico de la parálisis facial idiopática (PFI) para la que existían grandes controversias sobre las mejores conductas farmacológicas (ej. coticoides sistémicos y antivirales antiherpéticos) a prescribir. Los resultados del trabajo de Sullivan y col. que las autoras resumen en esta nota farmacológica, respaldan el buen pronóstico de los pacientes con PFI (tasa de recuperación completa de $65 \%$ a los tres meses y de $85 \%$ a los nueve) y la utilidad del tratamiento con corticoides en forma temprana (19\% de beneficio atribuible a los tres meses y casi $12 \%$ a los nueve meses) y no así el de aciclovir, que no mostró beneficios.

\section{Abstract}

This article describes clinical evolution and prognosis of idiopathic facial paralysis, a disease for which great controversies around optimal pharmacological management (ie: systemic steroids and antivirals active against herpes virus) exists. The authors of this article comment on the work of Sullivan and col., which supports the good prognosis of patients with facial paralysis (complete recovery rate at 3 months $=65 \%, 6$ months $85 \%)$ and the usefulness of early steroid treatment $(19 \%$ attributable benefit at 3 months and almost $12 \%$ at 9 months) vs acyclovir, which showed no benefit.
\end{abstract}

Palabras clave: parálisis facial idiopática, parálisis de Bell, tratamiento. Key words: idiopatic facial paralysis, Bell palsy, therapeutics.

Brosens C, Botargues M. ¿Son útiles los corticoides y los antivirales en el tratamiento de la parálisis facial idiopática? Evid. actual. práct. ambul; 11(4): 124125 Jul-Ago.2008.

\section{Introducción}

La parálisis facial idiopática o parálisis de Bell, es una parálisis facial periférica aguda, de causa desconocida. Se ha aceptado que en la mayoría de los casos, la causa más probable sería la activación del virus herpes simplex tipo 1, seguida en orden de frecuencia por la infección del virus herpes zóster

Entre otras causas infecciosas menos frecuentes se incluyen al citomegalovirus, el virus epstein bar, adenovirus, rubéola, sarampión, influenza B y coxackie. Entre las causas no infecciosas se proponen la isquemia del nervio facial y la predisposición hereditaria.

La incidencia anual de la parálisis de Bell es de aproximadamente 13 a 34 casos por 100000 personas.

\section{Diagnóstico}

El diagnóstico de la parálisis facial periférica es clínico ${ }^{1}$ y se basa en la instalación súbita (horas o días) de debilidad facial unilateral, que compromete a los músculos de la mitad superior e inferior de la cara. Se caracteriza por imposibilidad para cerrar el ojo, aparición del fenómeno de Bell -desviación del ojo hacia arriba cuando se intenta cerrar el párpado- desaparición de los surcos frontales y del surco nasolabial, y desviación de la comisura labial hacia el lado contralateral. Se diferencia de la parálisis facial central, ya que esta última afecta únicamente a los músculos de la mitad inferior de la cara. Su curso es rápidamente progresivo alcanzando la máxima intensidad de la parálisis entre las primeras 48 horas y las tres semanas consecutivas a la instalación, con recuperación total o parcial dentro de los seis meses.

Los estudios por imágenes sólo son necesarios si los hallazgos del examen físico son atípicos, si la progresión es lenta y se extiende más allá de las tres semanas, o si no existe mejoría a los seis meses.

El $70 \%$ de los pacientes logra una recuperación completa en forma espontánea, y el $84 \%$ consigue una función casi normal. El pronóstico está relacionado con la severidad de la lesión. Las lesiones clínicamente incompletas (debilidad parcial) tienden a la recuperación completa, con una tasa de recuperación del $94 \%$, en comparación con el $60 \%$ en aquellos pacientes con parálisis facial completa. En general, el pronóstico es favorable si puede verse algún grado de recuperación dentro de las primeras tres semanas desde la instalación.
No existen factores de riesgo que permitan predecir el pronóstico, que ayuden a determinar qué pacientes se beneficiarán con un tratamiento temprano, y/o que discriminen quienes no lo necesitarán ya que tendrán una recuperación espontánea.

\section{Tratamiento}

El tratamiento de la parálisis facial sigue siendo muy controvertido, ya que la tasa de recuperación espontánea se aproxima al $70 \%$, y la evidencia de la que disponemos respecto de la efectividad de los distintos tratamientos es insuficiente. Sin embargo, se han probado diferentes estrategias para el tratamiento de la parálisis facial idiopática²:

- Cuidado ocular: para evitar lesiones de la córnea en pacientes con compromiso del cierre palpebral y/o la secreción lacrimal. Lágrimas artificiales en forma horaria, anteojos protectores durante el día, ungüentos oculares y/o parche oclusivo durante la noche.

- Corticoides: el uso de corticoides sistémicos para el tratamiento de la parálisis facial es muy controvertido; y si bien pocos ensayos clínicos aleatorizados y metaanálisis demostraron un beneficio, estos incluyeron a un número limitado de pacientes como para poder sacar conclusiones definitivas.

- Antivirales: algo similar sucede con el tratamiento antiviral, existiendo algunos ensayos clínicos aleatorizados de buena calidad metodológica que arrojaron resultados controvertidos, y que permiten concluir que los antivirales no deberían ser utilizados como tratamiento único, sino sólo en combinación con los corticoides.

Recientemente y con el objetivo de esclarecer las controversias existentes acerca del tratamiento de la parálisis facial idiopáti$\mathrm{ca}$, ha sido publicado un ensayo clínico controlado ${ }^{3}$, aleatorizado y doble ciego con corticoides y antivirales (como tratamiento único o en forma combinada).

El estudio fue realizado en 17 hospitales de Escocia, el reclutamiento de los pacientes se llevo a cabo entre 2004 y 2006, y el seguimiento se realizó durante nueve meses. Fueron incluidos 551 pacientes mayores de 16 años con diagnóstico de parálisis facial periférica -415 referidos por un médico de familia y 41 por el departamento de emergencia-, reclutados dentro de las 72 horas del comienzo de los síntomas, y asignados

§ Servicio de Medicina Familiar y Comunitaria del Hospital Italiano de Buenos Aires. catalina.brosens@ @ospitalitaliano.org.ar 
aleatoriamente a recibir diez días de tratamiento con prednisolona, aciclovir, ambos agentes, o placebo.

Se compararon los resultados de los siguientes cuatro grupos: 1) prednisolona ( $25 \mathrm{mg}$ dos veces por día) más placebo (138 pacientes); 2) aciclovir (400mg cinco veces por día) más placebo (138 pacientes); 3) prednisolona más aciclovir (134 pacientes); 4) placebo más placebo (141 pacientes).

El resultado final primario fue la recuperación de la función del nervio facial según la escala de House-Brackmann; y los resultados finales secundarios incluyeron calidad de vida, apariencia física, y dolor.

La edad media de los pacientes fue de $44+/-16,4$ años, y los cuadros, en su mayoría moderados o severos. El 53,8\% inició el tratamiento durante las primeras 24 horas del comienzo de los síntomas, el $32,1 \%$ durante las 48 horas y el $14,1 \%$ durante las 72 horas, con una adherencia al tratamiento cercana a $90 \%$. Fueron evaluados a los tres meses para determinar el grado de recuperación y, si en esta instancia, la recuperación era incompleta -dos o más grados en la escala de HouseBrackmann- se los volvía a evaluar a los 9 meses.

De los 496 pacientes que completaron el estudio, 357 presentaron una recuperación completa dentro de los primeros tres meses; 80 lo hicieron dentro de los nueve meses, y 59 pacientes quedaron con un déficit residual.

A los tres meses, se evidenció una recuperación completa en el $83 \%$ de los pacientes que había recibido prednisolona como único tratamiento; en comparación con el $63,6 \%$ de los pacientes que no la habían recibido (OR 2,44; IC95\% 1,55 a 3,84 ); lo que demuestra una diferencia clínicamente significativa del $19,4 \%$ entre ambos grupos (NNT: 6 ).

No se observó una diferencia significativa en las tasas de recuperación completa entre el grupo que había recibido aciclovir $(71,2 \%)$ el que no la había recibido $(75,7 \%)$ con una diferencia no significativa: 4,5\% (IC95\%; -12,4 a 3,5). A los nueve meses, la tasa de recuperación completa fue de $94,4 \%$ para los pacientes que habían recibido prednisolona, y del $81,6 \%$ para aquellos que no la habían recibido, observándose una diferencia clínicamente significativa del 12,8\% (IC95\%; 7,2 a 18,4) y un NNT de 8. En esta instancia, tampoco se observaron diferencias significativas entre quienes habían recibido aciclovir y quienes no lo habían recibido.

En cuanto a la comparación a los tres meses de los tres grupos de tratamiento activo con placebo, la mayor chance de recuperación la tuvieron (quienes habían recibido recibido prednisolona sola, con un OR de 2,58 (IC95\%; 1,37 a 4,88); seguidos de quienes habían recibido tratamiento combinado con un OR de 1,73 (IC95\%; 0,96 a 3,12);) y por último por quienes habían recibido aciclovir como tratamiento único, con un OR 0,85 (IC95\%; 0,49 a 1,47).

A los nueve meses los resultados fueron similares, concluyéndose que la prednisolona fue altamente efectiva como monoterapia, y en menor medida, combinada con el aciclovir. Por otro lado, el aciclovir resultó inefectivo como tratamiento único, y tampoco se observó un beneficio mayor en el tratamiento combinado respecto de la monoterapia con prednisolona.

No se observaron diferencias significativas entre los grupos respecto de los resultados finales secundarios y sólo se reportaron tres muertes no relacionadas con el tratamiento.

Respecto de los pacientes asignados a recibir sólo placebo, presentaron una tasa de recuperación completa de $64,7 \%$ a los tres meses y de $85,2 \%$ a los nueve meses.

\section{Conclusiones}

Los resultados de este trabajo confirman que la tasa de recuperación espontánea de los pacientes con parálisis facial idiopática es alta y respaldan la indicación de tratamiento temprano con prednisolona (dentro de las primeras 72 horas del comienzo de los síntomas). Por otro lado, muestran que el tratamiento con aciclovir no sería beneficioso.

Teniendo en cuenta que se trata de un tratamiento efectivo, de bajo costo, y con pocos efectos adversos, podemos recomendar con confianza la utilización de prednisolona oral en aquellos pacientes con diagnóstico temprano de parálisis facial idiopática.

\section{Referencias}

1. Ronthal M. Bell's palsy. In: UpToDate, Rose, BD (Ed), UpToDate, Waltham, MA, 2006.

2. Bauso D. Parálisis facial idiopática o parálisis de Bell. Evid. Act. Pract. Ambul. 9 (1): $22-25$ En-Febr. 2006.

3. Sullivan F, Swan I, Donan P y col. Early Treatment with Prednisolone or Acyclovir in Bell's Palsy. N Engl J Med 2007; 357: 1598-607. 